\title{
TECHNIQUE AND EXPERIENCE OF SEISMIC ZONING OF THE CITIES OF ULAANBAATAR AND ERDENET
}

\author{
V.I. Dzhurik ${ }^{1}$, Ts. Batsaikhan ${ }^{2 *}$, S.P. Serebrennikov ${ }^{1}$, M. Ulziibat ${ }^{2}$, E.V. Bryzhak ${ }^{1}$, A.Yu. Eskin ${ }^{1}$ \\ ${ }^{\prime}$ Institute of the Earth's Crust SB RAS, Lermontov St., 128, Irkutsk, Russia \\ ${ }^{2}$ Research centre of astronomy and geophysics of the Mongolian academy of sciences, Ulaanbaatar, Mongolia \\ *E-mail: batsaikhan523@yahoo.com
}

\begin{abstract}
Optimum approach to an engineering-seismological assessment of mastered territories in regions of the Mongol-Baikal seismic zone is developed. On this basis seismic zoning of the cities of Ulaanbaatar and Erdenet is carried out. As a result schematic maps of the studied cities are made and the short characteristic of the allocated zones is given on the basis of calculated and experimental values of seismic effects parameters for the predicted large earthquakes.
\end{abstract}

Key words: Ulaanbaatar, Erdenet, seismic hazard, peak accelerations.

\section{INTRODUCTION}

A generalization is made concerning the results of seismic zoning of the study-intensive areas of Mongolia conducted by the researchers from the Institute of the Earth's Crust SB RAS and Research Centre of Astronomy and Geophysics MAS by the example of the cities of Ulaanbaatar and Erdenet.

Ulaanbaatar is the capital of Mongolia located in the Tola River valley (Selenga River basin), with the population of about one million people and a total area of $4800 \mathrm{~km}^{2}$ (1995-1996), $520 \mathrm{~km}^{2}$ of which are built-up. Erdenet, the third-largest city of Mongolia located in the Selenga and Orkhon interfluve region, is the center of the Orkhon aimak whose population is 83.2 thousand people (2006) and area of the zoned and industrial part is no less than $100 \mathrm{~km}^{2}$.

One of the main unfavorable natural factors for the population of these cities is associated with earthquakes because the city areas are situated in the Mongolian-Baikal seismic zone, one of the most seismically active on the Earth.

It is noted that for the areas of Erdenet and Uaanbaatar cities plans for their general construction have been repeatedly compiled, but to present day there are no approved initial seismicity maps on a probability basis and seismic hazard zoning maps of these areas on a scale of construction. On this point research studies represented by us are generalizing to some extent. As a first approximation they yield reasonable results that are necessary for compiling plans for the cities general construction and design of earthquake resistant constructions within the seismic zones, allocated by us.

It is worthy of note that the master site development plans were made repeatedly for Ulaanbaatar and Erdenet though there are still no approved maps of seismic zoning of these areas. 


\section{MATERIALS AND METHODS}

Analysis has been made on the seismogeological, seismotectonic and seismological data and substantiation has been performed for the large probable earthquake parameters with respect to the cities of Ulaanbaatar and Erdenet. The maps of seismic hazard are drawn based on the instrumental and computational methods of studies. The former may be divided into seismogeological and geophysical. Among the seismogeological methods are those based on recording and joint analysis of the motions associated with different sources (amplitude-frequency method) in different ground conditions. Seismic microzoning based on earthquake records is commonly referred to as direct seismic microzoning. Among the indirect methods, the most common are acoustic impedance and microseismic methods. Mobility, methodical substantiation and possibility to study vast areas using these methods provide their wide application in seismic microzoning practice, both in Mongolia, and in Russia [1].
Technical approaches have been proposed for forming a signal, which corresponds to the initial seismicity of the areas, with the records of rather large local events $(\mathrm{K}>12)$ [2]. Based on large earthquakes parameters and their range of variation for the investigated area we have synthesized the initial accelerograms for horizontal (NS) component by the procedure described earlier $[\mathbf{3}, \mathbf{4}]$, and improved by using new approaches. The accelerograms are normalized to rock foundation (fig. 1), their basic parameters for the cities of Erdenet and Ulaanbaatar are the following: peak acceleration values of solid rocks for the horizontal component are 106 and $60 \mathrm{~cm} /$ $\mathrm{s}^{2}$, maximum spectral values are 21 and 13.5 $\mathrm{cm} / \mathrm{s}$, and the frequencies of the principal peaks in the spectra are respectively 2.49 and $1.25 \mathrm{~Hz}$. It is important that the formed signals at the level of 0.7 from a maximum have width of spectra from 1 to $5 \mathrm{~Hz}$ - Erdenet and from 1 to $7 \mathrm{~Hz}$ - Ulaanbaatar. That is they correspond to both rather far and close earthquakes.
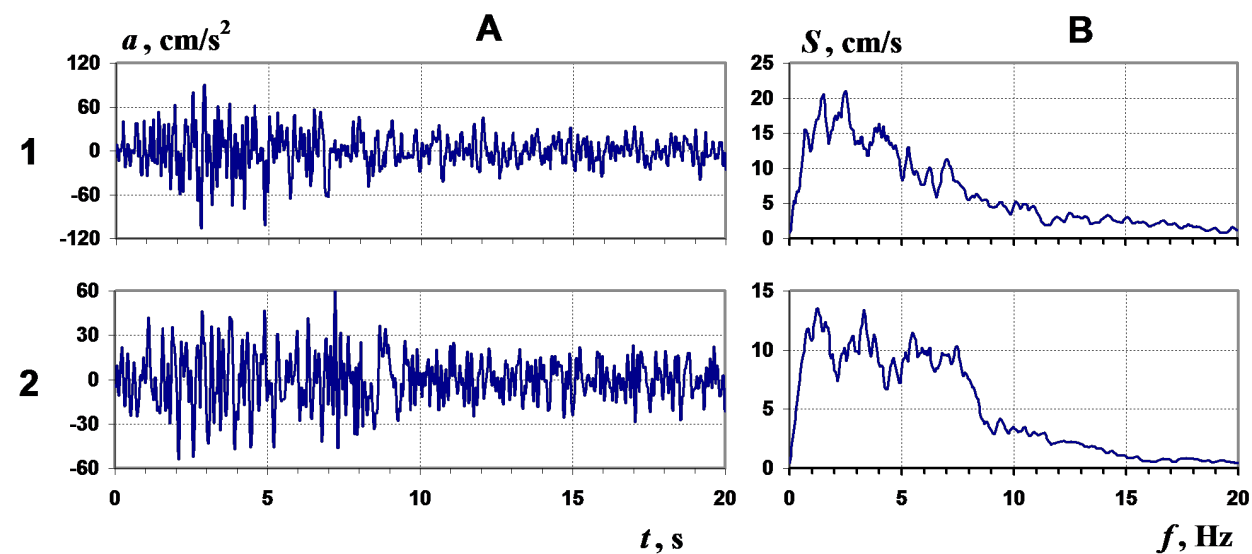

Fig.1. Accelerograms (A) and their amplitude spectrum (B), corresponding to models of «etalon» rocky soils, for probable large earthquakes for the territories of the cities of Erdenet (1) and Ulaanbaatar (2).

The initial accelerograms synthesized for the first category grounds are the most substantiated for the areas of Erdenet and Uaanbaatar cities and according to their parameters correspond to earthquakes with intensity 7 and 6. [5]. Therefore they were reasonably used as an initial signal to calculate the required parameters of seismic effects for a whole variety of ground conditions of projects under constructions.

At creation of maps the offered by us technique of seismic zoning of territories of the 
cities using seismic ground models is realized [6]. It allows to receive a full set of necessary parameters of seismic effects for building of earthquake resistant constructions and proves probability of seismic effects according to the accepted level of initial seismicity. The main stages of this technique of seismic zoning of territories of the cities are reduced to the following.

1. The complex analysis of initial geologicgeophysical and seismological materials, justification of zones of the probable earthquakes sources, specification of limits of initial seismic hazard when using data on these zones. Determination of basic parameters of the probable large earthquakes corresponding to initial seismicity.

2. Studying of seismic properties of the most widespread soils in the bases of constructions taking into account their composition and condition. Justification of a choice of parameters of etalon rocky soils. Carrying out seismic zoning according to measurements of speeds of seismic waves in prevailing on composition and condition soils and representative sites.

3. Generalization and the analysis of the close earthquakes registration data on the sites with representative soil conditions. Synthesis of initial signals for the "etalon" rocky grounds with intensity corresponding to initial seismicity of studied areas. Creation of a sufficient set of probable seismic models, calculation of a set of basic parameters of seismic effects and seismic zoning of the territory of the city.

\section{The results of research and their discussion}

Erdenet city territory. According to the map of seismic zoning [7] initial seismicity of Erdenet is estimated at 8 with index 2. It means that the territory of the city will be exposed to the seismic effect with intensity 8 once in 1000 years. The probability of exceeding of calculated intensity 8 , for such frequency of seismic events within 50 years (average service life of buildings), is estimated at $5 \%$
On the basis of realization of the offered technique for seismic zoning of territories of the studied cities we received the main characteristics and parameters of seismic effects. Part of them - seismic waves velocities, accelerograms, spectrum of accelerations, frequency characteristics and their parameters are received directly for the main types of soil in their various conditions. Other parameters including seismic intensity was defined by the way of carrying out necessary calculations. Seismic zoning is carried out on seismic soil models, each of them is described by a set of the parameters stated above.

Engineering-geological data, typical profiles, data on the thickness of friable deposits and depth of level of the ground waters received according to drilling and near surface geophysics formed a basis for creation of seismic soil models. At the final stage of researches typification of seismic soil models for concrete territories of construction is realized and calculation for them probable seismic effects in form of accelerograms with the corresponding periods, duration of fluctuations and other characteristics considering parameters of probable earthquake source zones is carried out.

We suppose that the chosen technique for seismic microzonation of the cities of Erdenet and Ulaanbaatar through creation of seismic soil models and using them for seismic zoning of the territory of the city represent optimum and economic option of an engineering and seismological assessment of studied territories.

that corresponds to admissible risk of $95 \%$ [8]. If such events repeat 1 time in 500 years, their probability is estimated at $10 \%$, or will correspond to admissible risk in $90 \%$ of not exceeding of such events, within 50 years as well.

For the solution of engineering and seismological tasks, according to the stages of works stated above, and forming of a sufficient 
set of seismic soil models were made maps of thickness of friable deposits, depths of ground waters level, seismic waves velocities for friable and rocky soil. In total for the territory of the city 32 models were used. Generally, the number of models for the studied territory is defined by an error of creation of model and an admissible error of heterogeneity in a scale of construction. We show 16 of them which characterize the main variety of soil conditions of construction (tab. 1). In the table the following measured and calculated parameters are specified: thickness of layers (h); velocity of P- (Vp) and S- (Vs) waves; density of soil $(\rho)$; resonance frequency of layers of friable soils (Fres); the maximum acceleration (Amax) for horizontal (EW) and vertical (Z) components, and seismic intensity (I). As a result each constructed model characterizes a certain site of the city.

Sites of near surface bedding of the disintegrated and fractured rocky soils are presented by 4 models (tab. 1, M 1-4). Models 1 and 6 correspond to etalon rocky (1st category) and average (2nd category) soils. Models 5-10 correspond to various thickness of waterunsaturated friable soils which increases from 6 to $120 \mathrm{~m}$. They have under them rocky soils with "etalon" values of velocities. For sites with various depth of level of ground waters 6 models 11-16 are given.

Calculation of seismic waves on a surface (accelerograms) was executed on a method of thin-layer medium [1] and using calculation and experimental frequency characteristics of a loose layers of various state and thickness [4]. As a result for model of a etalon and rocky soils the maximum values of accelerations for horizontal components of equal $106 \mathrm{~cm} / \mathrm{s}^{2}-$ EW and $40 \mathrm{~cm} / \mathrm{s}^{2}-\mathrm{Z}$ are obtained (tab. 1; fig. 2A, M-1). According to the scale of seismic intensity it corresponds to etalon seismic effect for rocky soils of the area, that equal to 7. For the etalon model, presented by average soils (tab. 1, M-6), the maximum acceleration can reach $231 \mathrm{~cm} / \mathrm{s}^{2}-E W$ and $80 \mathrm{~cm} / \mathrm{s}^{2}-\mathrm{Z}$ that corresponds to the seismic effect, equal to 8 and corresponding to initial seismicity of the area. Model of average water-saturated soils (tab. 1, fig. 2, M-13) is characterized by the these values of the maximum accelerations: $452 \mathrm{~cm} / \mathrm{s}^{2}-E W$ and $156 \mathrm{~cm} / \mathrm{s}^{2}-\mathrm{Z}$. In all calculations accelerogram, synthesized for model of rocky "etalon" soils (fig. 2A, M-1) was used as less distorted by near-surface nonuniformity.

For models 5-10 (water-unsaturated soils) results of calculations are reduced in table 1 and shown for models 6 and 8 in figure 2. In the range of change of friable deposits from 6-10 to $120 \mathrm{~m}$ acceleration of oscillations changes from 201 to $269 \mathrm{~cm} / \mathrm{s}^{2}$, with the maximum thickness they even decreased a little. Maxima of spectra with increasing of thickness increase from 36 to $65 \mathrm{~cm} / \mathrm{s}$ (fig. 2B). There is also a redistribution of their maxima on the frequency that a little displaced towards low frequencies with increase of thickness of friable deposits.

Calculation of seismic effects for partially or completely water-saturated friable soils is carried out for 6 models (No. 11-16), in the case of raising of level of ground waters on 5,3 and $0 \mathrm{~m}$ from the surface and the thickness of water-saturated soils from 10 to $80 \mathrm{~m}$. Calculations are carried out in the assumption that all energy of oscillations transforms to elastic deformations. The approach considering increasing in intensity of oscillations of the layer of water-saturated soils in relation to water-unsaturated, through calculation of relative experimental frequency characteristics was used. At such approach the value of accelerations for models 11-16 changes from 269 to $537 \mathrm{~cm} / \mathrm{s}^{2}$ (EW) and from 96 to $159 \mathrm{~cm} / \mathrm{s}^{2}(\mathrm{Z})$. The maximum values of spectra for horizontal component changes from 70 to $110 \mathrm{~cm} / \mathrm{s}$, and their maxima are at frequencies from 1 to $5 \mathrm{~Hz}$ (fig. 2B).

Increasing of intensity of oscillations for the constructed models at resonant frequencies (fig. 2C) affects change of the spectrum level of the initial signal at the same frequencies (fig. 2B). In total, increases in accelerations 


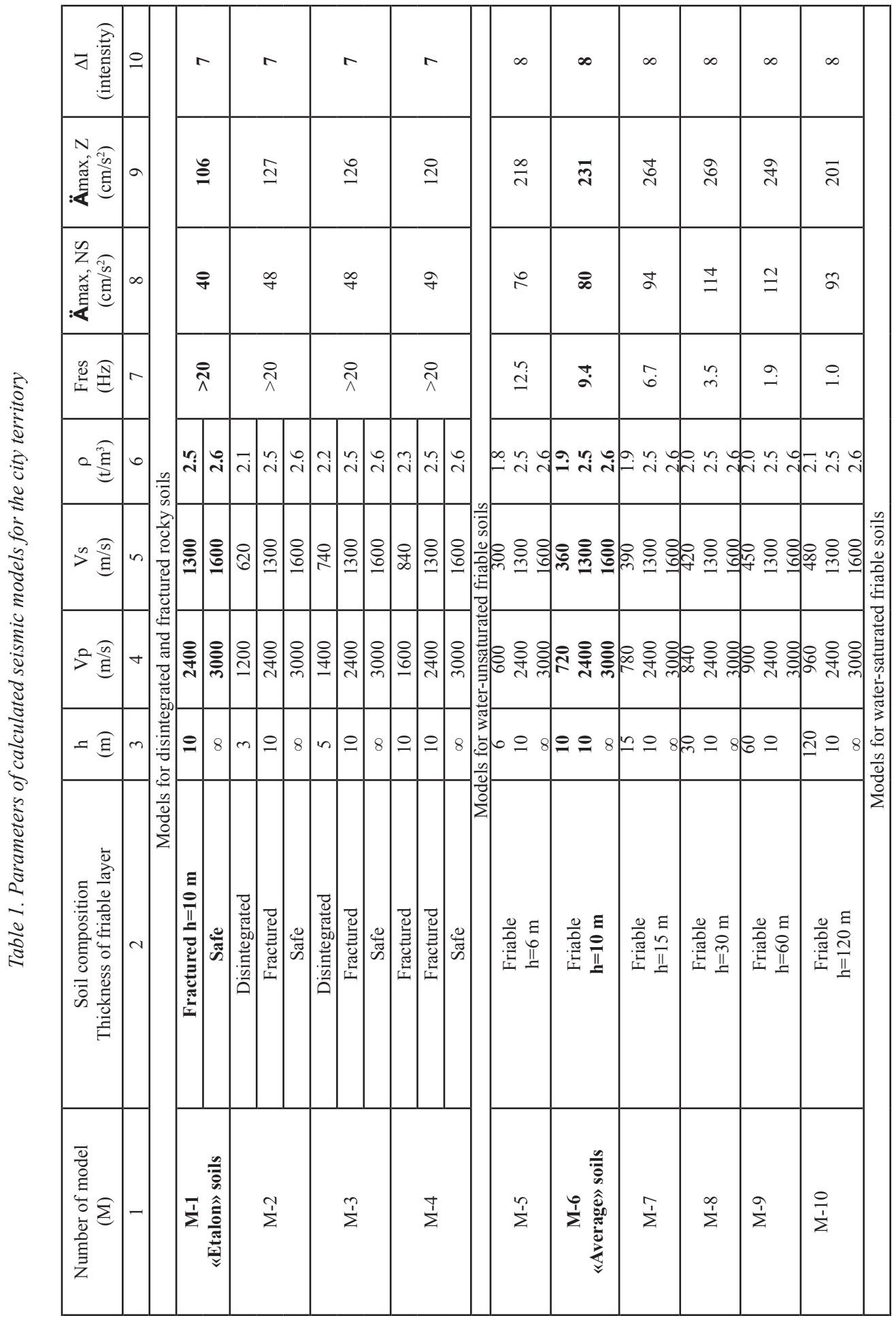




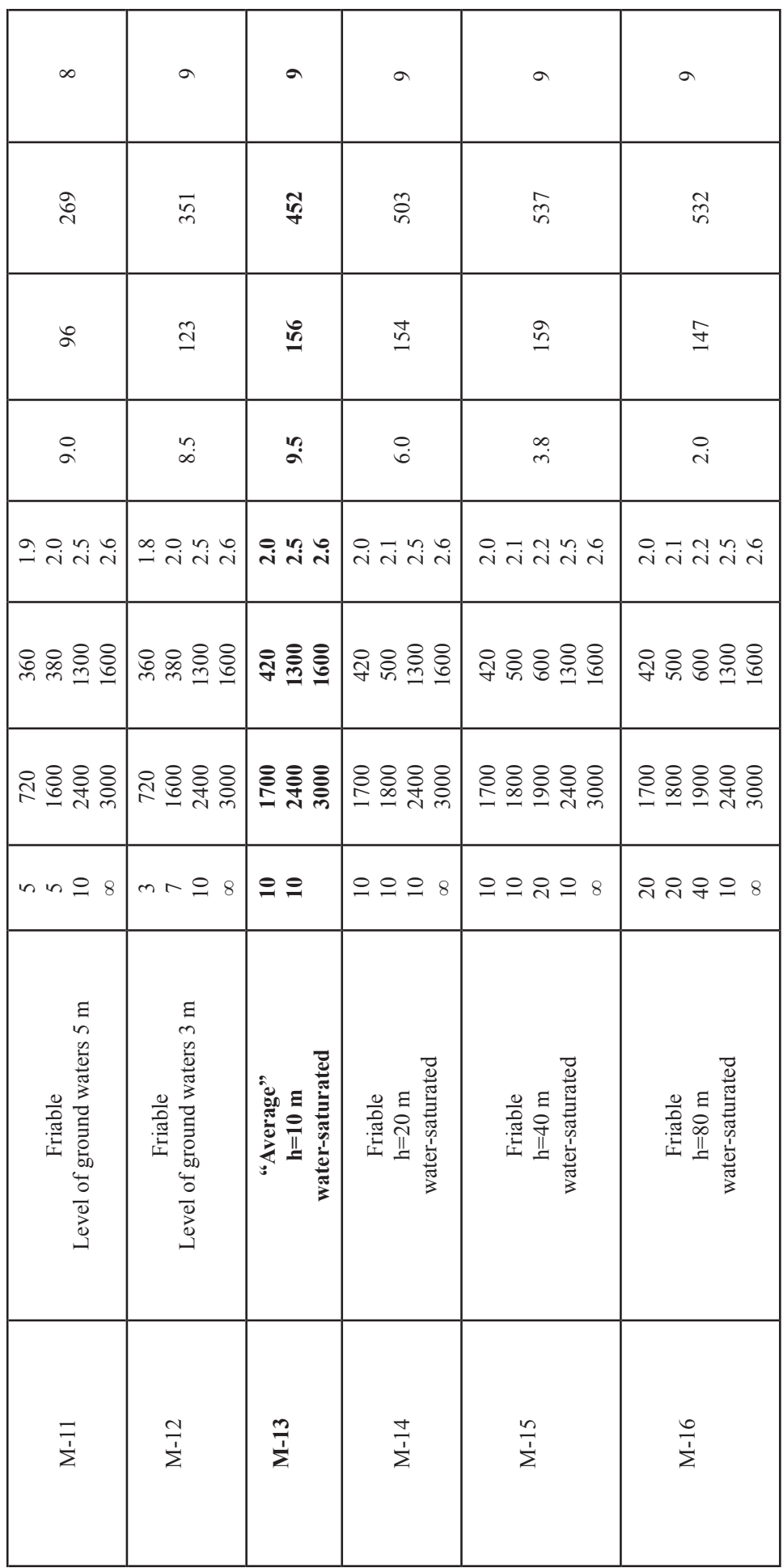


of seismic oscillations on accelerograms is caused by change of thickness and acoustic rigidity of soil layers, attenuation of seismic waves, the angle of seismic radiation and other characteristics of the medium on the way of initial seismic waves.

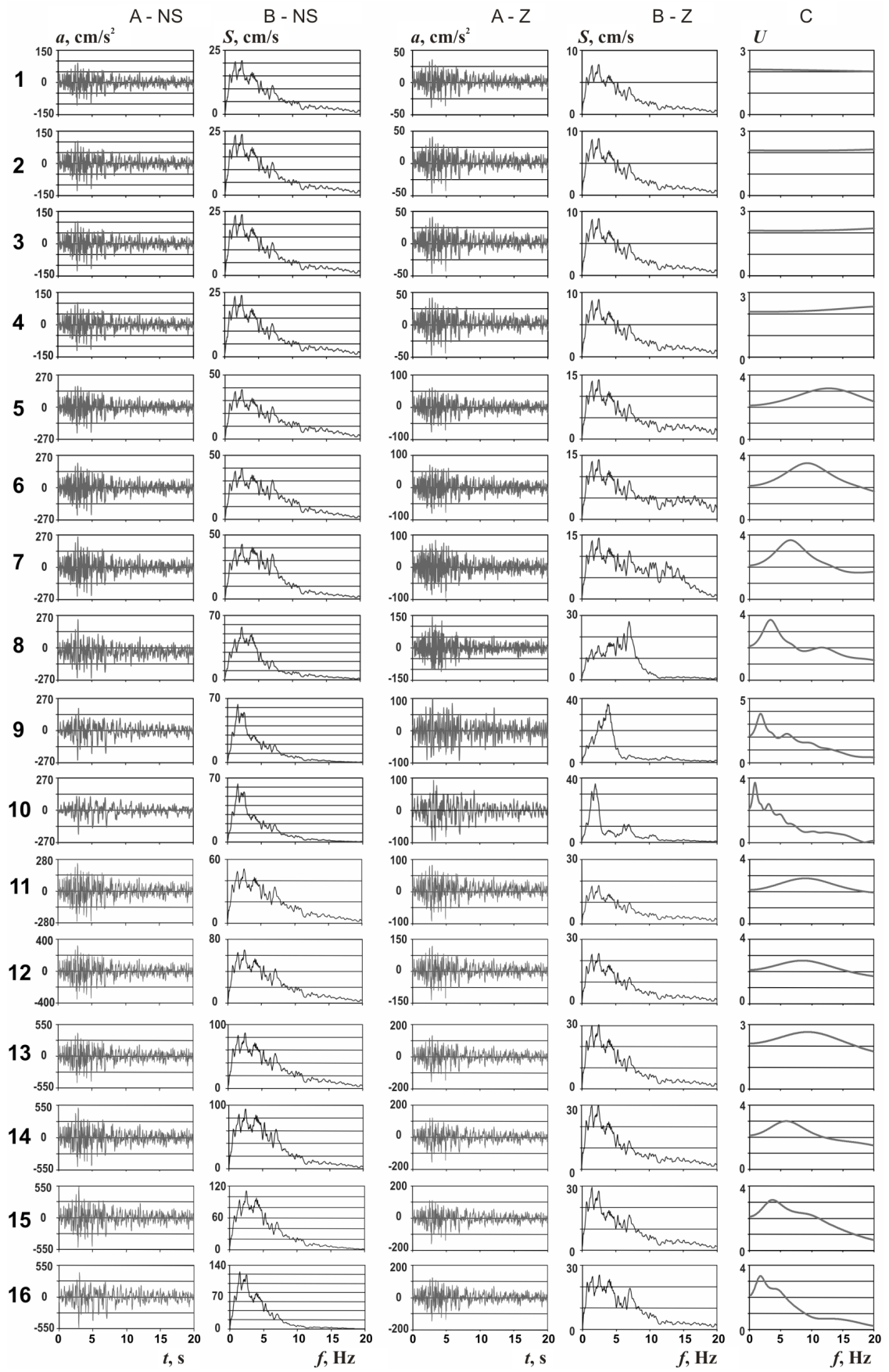

Fig. 2. Accelerograms (A), their spectrum (B) and frequency characteristic (C), calculated for horizontal (NS) and vertical (Z) components for models 1-16 (the numbers correspond to table 1). 
The basis of constructing of a 1:25000 scale schematic map for the area of Erdenet city was schematic map of engineering geology conditions and results of calculations of seismic hazard using methods of seismic rigidity and microtremor, estimated for each point of measurements. As a result the territory of the city was divided into sites with seismic intensity $7 ; 8$ and 9 as a first approximation (fig. 3). Further the characteristic of seismic hazard of these zones was added with data of calculation methods.

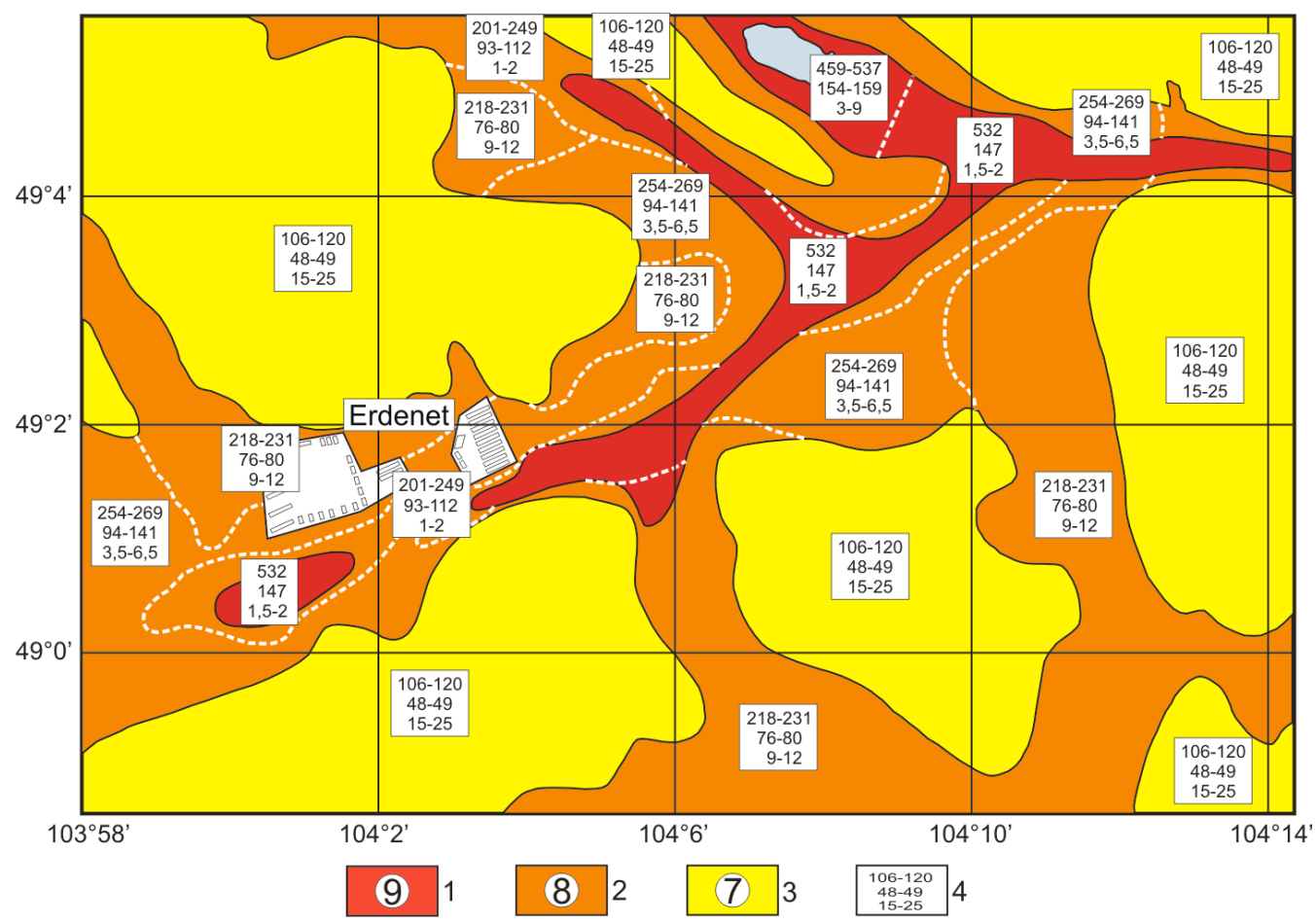

Fig. 3. The schematic map of seismic microzonation of the territory and area of Erdenet city. 1-zone of intensity 9;2-zone of intensity 8; 3-zone of intensity 7;4-from the top to the bottom: values of maximal accelerations for horizontal component (NS), values of maximal accelerations for vertical component $(Z)$ and resonance frequencies of friable layer.

The map is made to characterize each marked out by seismic hazard zone by several models, including and transitional zones. Besides, for each marked out zone on the case of the large earthquakes corresponding to initial seismicity of Erdenet city possible limits of values of the maximum accelerations for horizontal and vertical components and resonant frequencies of friable deposits are specified. These zones are in turn detailed with chosen possible basic parameters.

It has been stated, the areas of civil and industrial construction in the city of Erdenet are in zones of seismic intensity 8 and 9 ; the copper-molybdenum ore quarry is in zone of seismic intensity 7 . The built-up area projections may be designed for zones of seismic intensity 7 and 8 shown on the map of seismic zoning. The peak horizontal and vertical accelerations in the zone of seismic intensity 9 vary respectively from 106 to 537 $\mathrm{sm} / \mathrm{s}^{2}$ and from 40 to $159 \mathrm{sm} / \mathrm{s}^{2}$, the dominant or resonance frequency of the upper loose layer ranging from 1 to 12 or more $\mathrm{Hz}$. 


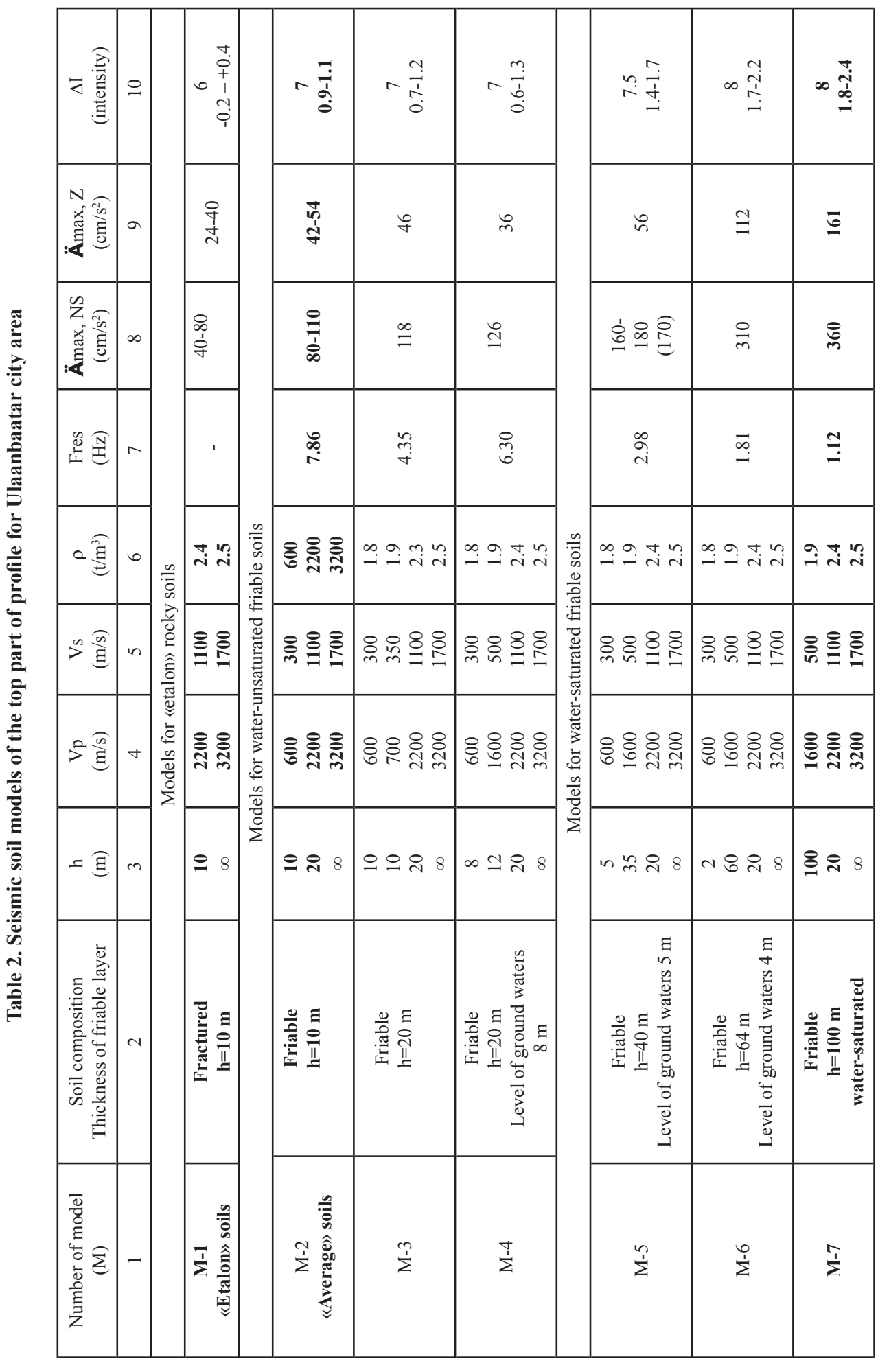




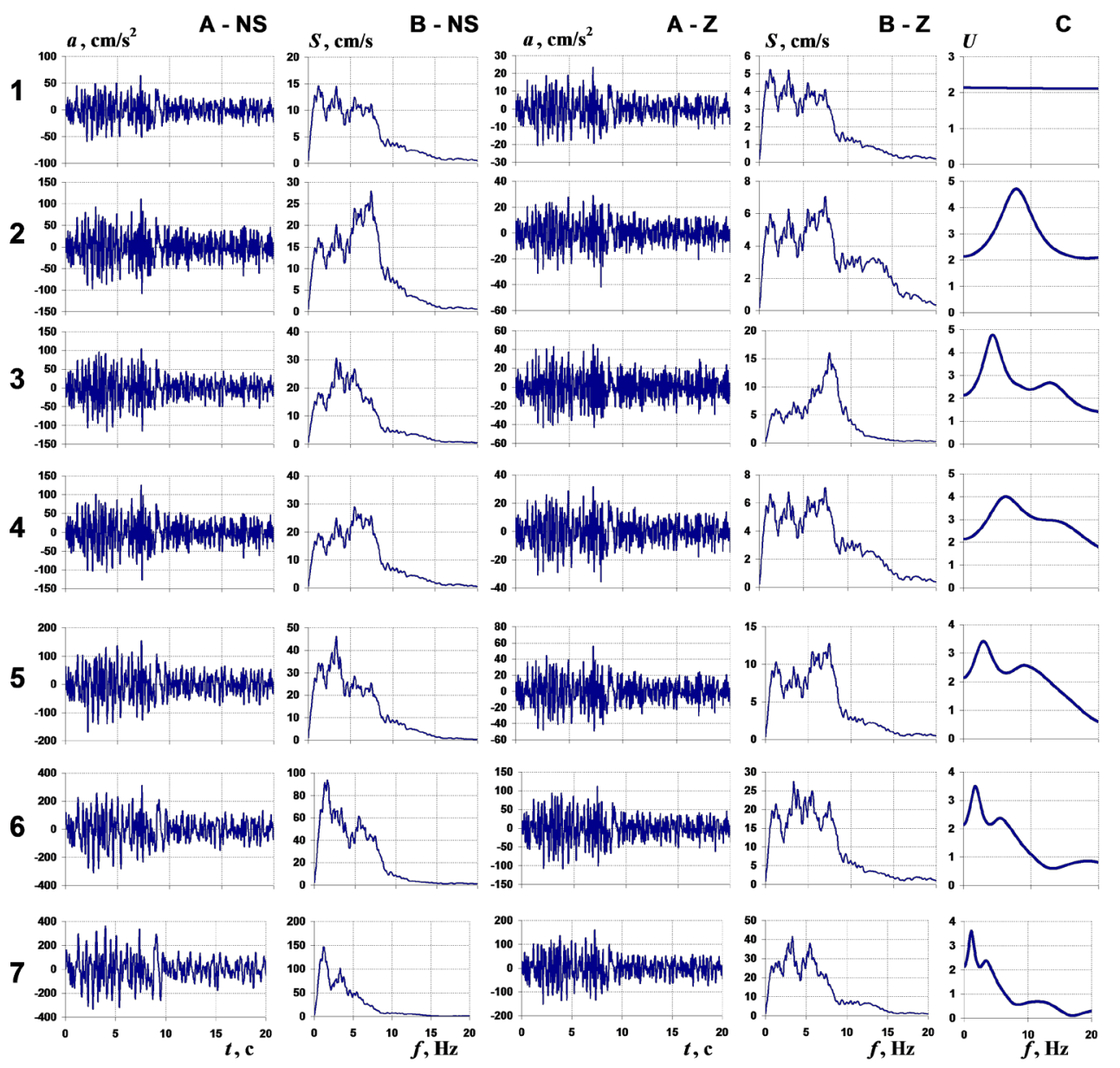

Fig. 4. Accelerograms (A), their spectrum (B) and frequency characteristics (C), calculated for horizontal (NS) and vertical (Z) components for models 1-8 (numbers correspond to table 2).

Ulaanbaatar city territory. Initial seismicity for the territory is accepted according to existing normative documents and equals to 7 , though this assessment is not declared for the modern seismic situation of the city [5]. As a first approximation basic parameters of earthquakes for the territory of Ulaanbaatar city can change in the following limits: the epicenter distance is $0-240 \mathrm{~km}$, magnitude 5.4-8.0, focal depth is $10-20 \mathrm{~km}$, the focal mechanism is strike slip and oblique reverse.

As well as for Erdenet, calculation of accelerograms is carried out, spectrum of accelerations and frequency characteristics by the technique stated above. For the constructed probable seismic models (about 30) basic parameters of seismic effects, that using for seismic zoning of the territory of Ulaanbaatar city, are received. For this purpose it was zoned previously by parameters of calculation models taking into account the analysis of engineering-geological and geophysical data [2]. In the present generalizing article in the same way for the first time calculations are carried out for vertical component, that has great importance for design of aseismic highrise buildings and possible close earthquakes. 
Results are presented in article for 7 constructed models in a tabular form (Tab. 2), in the form of calculation accelerograms, their spectrum and frequency characteristics (fig. 4) and a schematic map of seismic zoning of the territory of Ulaanbaatar with the maximum accelerations (fig. 5).

The constructed scheme of zoning of the territory of Ulaanbaatar (fig. 5) shows that the probable maximum seismic effects corresponding to accepted initial seismicity for the territory of the city can vary from 40 to 360 $\mathrm{cm} / \mathrm{s}^{2}$ for NS components and from 24 to 161 $\mathrm{cm} / \mathrm{s}^{2}$ for $\mathrm{Z}$ components, resonant frequencies of friable thickness of soils are ranging from 1.12 to $10 \mathrm{~Hz}$. Increments of the seismic intensity relative to "etalon" rocky soils, caused by variation of acoustic rigidities and the depth of ground waters, varies from -0.1 to 2.4 [1]. As a result the territory of the city is divided into 6, 7 and 8 of seismic hazard. (fig. 5).

The zone of seismic intensity of 6 . This territory is presented by rocky soils, they form crystalline basement of the territory and presented by sandstones, shales, limestones and granitoids. Near-surface soils are disintegrated and fractured. Thickness of quaternary deposits is usually less than 3 meters. This zone is presented by model 1 (tab. 2 ; fig. 4,1 ). The range of variation of maximal accelerations for the territory presented by this model for horizontal component is from 40 to $80 \mathrm{~cm} / \mathrm{s}^{2}$ and vertical is from 24 to $40 \mathrm{~cm} / \mathrm{s}^{2}$, resonant frequencies are more than $9 \mathrm{~Hz}$ (fig. $4,1 \mathrm{C}$ ). The maximum of spectra is $14.6 \mathrm{~cm} / \mathrm{s}$ - NS and $5.24 \mathrm{~cm} / \mathrm{s}-\mathrm{Z}$, the width of spectra with level equal to 0.7 of maximum is at frequencies from 0.63 to $7.52 \mathrm{~Hz}$ (fig. 4, 1B).

The zone of seismic intensity of 7 . Dealluvial complex (descent deposits crushed stone, debris) is located in elevated sites and above rocky soils, their thickness is from 5-6 to 20 and more meters. If there are ground waters, their level is 7-10 meters from the surface. This zone is presented by models
2-4 (tab. 2; fig. 4, 2-4). The range of variation of maximal accelerations for the territory presented by these models for horizontal component is from 80 to $126 \mathrm{~cm} / \mathrm{s}^{2}$ and vertical is from 36 to $54 \mathrm{~cm} / \mathrm{s}^{2}$, resonant frequencies are within the limits of 4.35-7.86 Hz (fig. 4, $2-4 C)$. The maximums of spectrum are equal to $28-30.6 \mathrm{~cm} / \mathrm{s}-\mathrm{NS}$ and $7.06-16.1 \mathrm{~cm} / \mathrm{s}-\mathrm{Z}$, the width of spectra with level equal to 0.7 of maximum is at frequencies from 2.78 to 8.06 $\mathrm{Hz}$ (fig. 4B).

The zone of seismic intensity of 8 . Alluvial complex forms flood plain of Tuul river valley. Usually, these are gravel-pebbly soils with sandy-loamy filler, water-saturated within water horizon. The thickness of friable deposits from the sides of the cavity to main river-bed varies from several meters to 100 and more (last statement demands of further specifications). Alluvial-proluvium complex (gravel-pebble formations) is located within talus fan of Selbe and Uliastai rivers. The maximal thickness (up to 20 meters) corresponds to river-mouth parts of talus fan. Water-saturating of soils starts from the depth of 4-5 meters, and during summer floods and within waterlogged sites raising of level ground waters to the surface is possible. These zones are presented by models 5-7 (tab. 2; fig. $4,5-8)$. The range of variation of maximal accelerations for the territory presented by these models for horizontal component is from 160 to $360 \mathrm{~cm} / \mathrm{s}^{2}$ and vertical is from 56 to $161 \mathrm{~cm} / \mathrm{s}^{2}$, resonant frequencies are within the limits of 1.12-2.98 Hz (fig. 4, 5-7C). The maximums of spectrum are within the limits of $46.1-147 \mathrm{~cm} / \mathrm{s}-\mathrm{NS}$ and $12.8-41.6 \mathrm{~cm} / \mathrm{s}-\mathrm{Z}$, the width of spectra with level equal to 0.7 of maximum is at frequencies from 0.38 to 3.86 $\mathrm{Hz}$ (fig. 4B).

It is significant that specified on the map (fig. 5) values of maximal accelerations and resonance frequencies are most possible for detailed zones and correspond to the level of seismic effect accepted for initial seismicity of the territory of Ulaanbaatar city. 


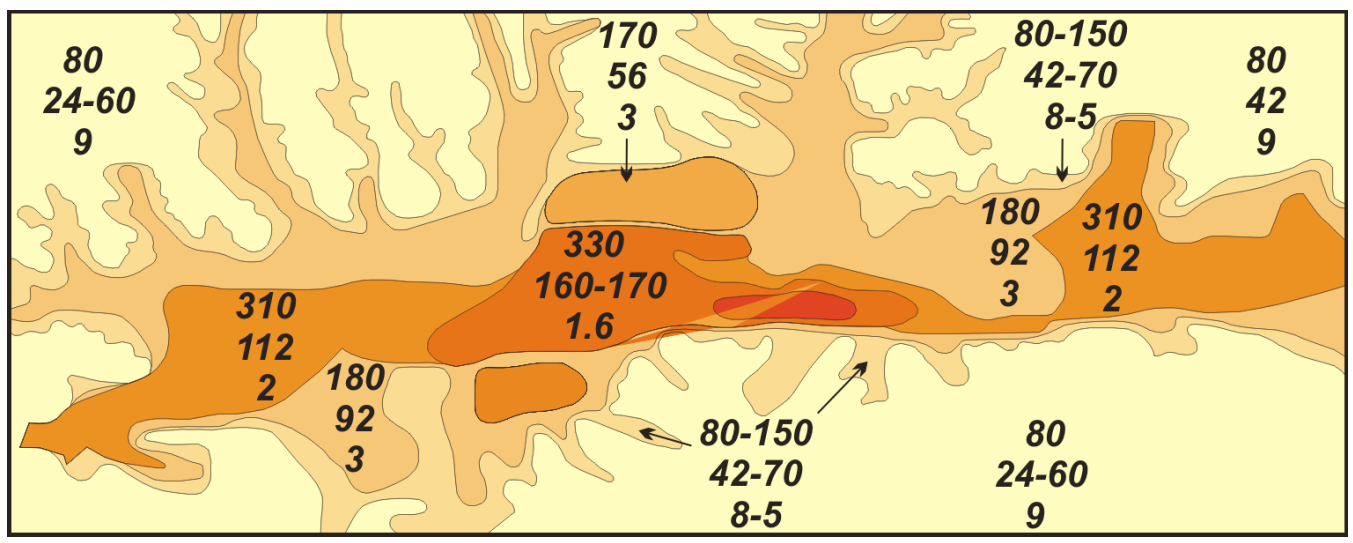

Fig. 5. The scheme of zoning of the Ulaanbaatar city territory with maximal accelerations of NSand Z-component (at the top) and frequency characteristics (at the bottom).

Building in the capital of Mongolia has increased rates, the number of storeys grew up in recent years. The number of buildings higher than 12 floors considerably increased (such buildings demand of additional costs of ensuring their seismic stability). High-rise buildings will experience rather increased reaction with identical seismic effects on the bases of buildings under construction. Besides at present time the sites located in valleys of the rivers Selbe, Uliastay, Tolgoyt and Tola are mainly built up. They are the most seismic unfavorable sites, because of big thickness of friable water-saturated soils of various composition. Their seismic hazard should be studied by direct methods of seismic zoning. Such tasks can be solved by the way of deployment of engineering seismological polygon for the capital of Mongolia. Results of such researches will be directed at increasing requirements to engineering seismological justification of construction conditions not only for all city, but also for concrete building sites [9]. It leads to necessity of increasing details of researches and as a result to construction rise in price. In this case citizens win for which increasing seismic stability of buildings under construction creates a guarantee of safety of their accommodation.

As a first approximation in our case researches are conducted taking into account the initial seismicity proved for mass construction, it is a $10 \%$ risk of probability of excess (or $90 \%$ probability of not exceeding) calculated intensity within 50 years. If initial seismicity is changed or even the class of responsibility of constructions will be raised by designers due to their number of storeys, it is necessary to reconsider and results of calculations of seismic effects with new level of probabilistic estimates.

\section{Conclusion}

The research results are partial generalizing of previous joint studies and an initial stage of the engineering-geological substantiation for building conditions of the cities of Mongolia, based on the probability estimate of their seismic hazard. Consideration is being given to a variety of problems: from studying specific features of earthquake sources and attenuation of seismic waves as they move as they travel away from the source to assigning an initial signal, constructing models for probable earthquakes and calculating parameters of seismic effects for typical soil conditions. A quantitative assessment of seismic hazard 
for the areas of the cities is finally aimed at prediction of the effect of a large probable earthquake on ground layers serving as bases of constructions. In this respect the further analysis and specification of probabilistic estimates of possible large earthquakes in particular for Ulaanbaatar, Darhan and Erdenet cities is necessary. We suppose the most important is to carry out researches for indicating a role of fault tectonics in forming focus zones with earthquakes directly effecting on facilities and communications.

On the basis of the offered technique we calculated necessary parameters of seismic effects and the main seismic characteristics for seismic zoning of the studied territories. Part of them (velocities of seismic waves, accelerograms, spectrum of accelerations, frequency characteristics and their parameters) are obtained directly for the main types of soils in their various states and presented for the studied cities in a generalized form in the present article. Other parameters including seismic intensity was determined by carrying out necessary calculations and experimental data. Seismic zoning is made using the created models, each of them is described by a set of the parameters stated above and characterizes a certain site of the city.

\section{References}

1. Assessment of soil conditions impact on seismic hazard // Methodical guide to seismic microzonation. Moscow: Science, 1988. 300 pp. (in Russian)

2. Seismicity and seismic zoning of Mongolia Dzhurik, V.I., Klyuchevskii, A.V., Serebrennikov, S.P., Demyanovich, V.M., Batsaikhan, Ts. \& Bayaraa, G.. - Institute of the Earth's Crust SB RAS, Irkutsk, (2009), 420 pp. (in Russian).

3. Complex geophysical and seismological investigations in Mongolia. /Editors-inchief V.I.Dzhurik, T. Dugarmaa. - Ulaanbaatar - Irkutsk, 2004. - 315 p.

4. Seismic hazard zoning of the city of Erdenet / Dzhurik V.I., Serebrennikov S.P., Ryaschenko T.G., Batsaikhan Ts., Dugarmaa T., Ulziibat M., Eskin A.Yu., Usynin L.A. - Irkutsk: Institute of the Earth's crust SB RAS, 2011. - 122 pp. (in Russian)

5. Dzhurik V.I., Serebrennikov S.P., Klyuchevskii A.V., Batsaikhan Ts. Comprehensive assessment of seismic hazard for building construction sites in Ulaanbaatar city. // Earthquake engineering. Safety of structures. No. 5, 2009. Pp. 46-51. (in Russian)

6. Dzhurik V.I., Serebrennikov S.P., Batsaikhan Ts., Drennov A.F., Bryzhak E.V., Usynin L.A., Eskin A.Yu. Methods for seismic hazard zoning of MongolianSiberian region border territories (on an example of Erdenet city area). Irkutsk: The Bulletin of Irkutsk State University. Series «EARTH SCIENCES». - 2012. - V.5, No.1 - Pp. 118-142. (in Russian)

7. Earthquakes and fundamentals of seismic zoning of Mongolia. // Moscow: Science, 1985. 224 pp. (in Russian)

8. The map of general seismic zoning of the territory of Russian Federation. 1:8000000 scale. Moscow: Russian ministry of science and technology, 1999. 57 pp. (in Russian)

9. Dzhurik V.I., Dugarmaa T., Batsaikhan Ts., Serebrennikov S.P., Drennov F.A. The technique of seismic risk mapping for the territories of economic development of Mongolia//Proceedings of Mongolian Academy of Sciences. 2004. 16-29 p. 